\section{Welche Rolle spielt IgE in der Atherogenese?}

Freies IgE bindet über den FcદR1-Rezeptor an die Mastzelle und löst durch deren Aktivierung unter anderem allergische Prozesse aus. Doch auch Zelltypen, die im Rahmen der Atherogenese eine Rolle spielen, tragen einen FcદR1-Rezeptor. Eine Studie untersuchte mögliche Zusammenhänge an rund 1.000 Patienten.

A usgangspunkt der chinesisch-amerikanischen Studie waren auffallend erhöhte IgE-Spiegel im Serum von Herzpatienten. Diese korrelierten mit dem Schweregrad der Krankheit und erreichten nach einem Infarkt die höchsten Werte. Bestätigt wurden die Befunde durch immunhistochemische Untersuchungen, die in atherosklerotischen Läsionen IgE sowie die Rezeptoruntereinheit FcєR $1 \alpha$ in der Nähe von Makrophagenansammlungen erkennen ließen.

Um eine direkte Korrelation zwischen IgE und der Atherogenese zu untersuchen, kreuzten die Autoren atheroskleroseanfällige ApoE ${ }^{-/-}$-Mäuse mit $\mathrm{Fc}_{\mathrm{C}} \mathrm{R}^{-/}{ }^{-}$-Mäusen. Deren ApoE- und
FcєR1-defiziente Nachkommen zeigten im Vergleich zu den ApoE-/FcєR1 ${ }^{+}$Eltern nicht nur bis zu $75 \%$ geringere Fettablagerungen in den Gefäßen - es fanden sich auch eine verminderte Konzentration an Zytokinen sowie weniger Makrophagen und T-Zellen in atherosklerotischen Läsionen, was auf eine geringere Entzündungsreaktion in Abwesenheit des FcєR1-Rezeptors hinweist.

Ein ähnliches Bild zeigte sich, wenn anstelle des FcєR1-Rezeptors der TLR4Rezeptor ausgeschaltet wurde. Letzterer ist im Zusammenspiel mit FceR1 essenziell zur $\mathrm{Na}^{+} / \mathrm{H}^{+}$-Austauscher(NHE1)vermittelten Aktivierung von Makrophagen, Endothel- und glatten Gefäß-

\section{Der Histaminintoleranz auf der Gen-Spur}

\author{
Die Symptome der Histaminintoleranz werden überwiegend durch \\ eine verminderte Aktivität der Diaminoxidase verursacht. In einer \\ genetischen Assoziationsstudie wurde nach auffälligen Einzelnukleo- \\ tid-Polymorphismen bei verminderter Aktivität des Enzyms gesucht.
}

$\mathrm{H}$ istaminintoleranz wird heute als klinische Entität und häufige Ursache für eine Nahrungsmittelunverträglichkeit angesehen, verursacht durch einen verminderten Abbau von Histamin durch die Diaminoxidase (DAO). Symptome eines erhöhten Histaminspiegels sind u.a. gastrointestinale Störungen, Kopfschmerzen, Flushing, Rhinitis und ein asthmaähnliches Wheezing, die durch histaminarme Kost verhindert werden können. Etwa 1\% der Bevölkerung hat eine Histaminintoleranz, betroffen sind vor allem Frauen mittleren Alters.

Bei der genetischen Ursachensuche für eine verminderte DAO-Aktivität bei gesunden Personen wurden zwei Einzel-
nukleotid-Polymorphismen (,single nucleotide polymorphisms“, SNPs) in den Genen von DAO und der Histamin-NMethyltransferase (HNMT) identifiziert. In einer Fall-Kontroll-Assoziationsstudie wurden nun verschiedene DAO- und HNMT-SNPs von 285 Patienten mit Histaminintoleranz-Symptomen und 199 Kontrollpersonen untersucht.

Die DAO-Serumaktivität war signifikant mit sieben SNPs im DAO-Gen assoziiert. Reportergen-Assays mit dem SNP an rs2052129 zeigten eine geringere Promotoraktivität des Minorallels ( $\mathrm{p}=$ 0,016). Die DAO-mRNA-Expression in mononukleären peripheren Blutzellen bei homozygoten Trägern des Minor-

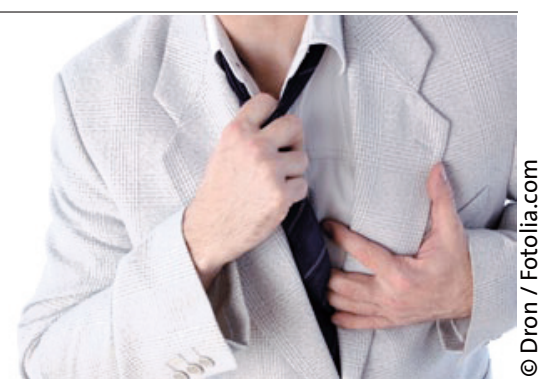

Wenn das Herz nicht mehr mitmacht, kann ein erhöhter IgE-Spiegel dahinterstecken.

muskelzellen und leitet schließlich die Apoptose ein.

Fazit: Die erhöhten IgE-Werte im Serum und das Vorkommen in atherosklerotischen Läsionen von Patienten mit instabilen Plaques stützen die Vermutung, dass IgE nicht nur an der Aktivierung von Mastzellen, sondern auch von anderen Entzündungszellen sowie Endothel- und glatten Muskelzellen der Gefäße im Rahmen einer Atherogenese beteiligt ist. Dr. Christine Starostzik

Wang J et al. IgE stimulates human and mouse arterial cell apoptose and cytokine expression and promotes atherogenesis in $\mathrm{ApoE}^{-/-}$mice. J Clin Invest 2011; 121: 3564-77

allels an rs2052129, rs2268999 und rs10156191 war signifikant niedriger ( $\mathrm{p}=0,002)$ als bei homozygoten Trägern des Majorallels. Variationen im DAOGen waren aber nicht assoziiert mit dem Phänotypus der Histaminintoleranz per se, sondern nur mit der DAO-Aktivität selbst sowie gleichzeitigem Vorliegen einer Histaminintoleranz und verminderter DAO-Aktivität.

Fazit: SNP-Varianten im DAO-Gen beeinflussen die DAO-Expression und die Aktivität. Die genetischen Varianten erscheinen aber nur als eine von mehreren Ursachen, die zur klinischen Manifestation einer Histaminintoleranz beitragen. Wahrscheinlich liegt auch bei dieser Erkrankung eine Wechselwirkung zwischen genetischen und Umweltfaktoren vor. Dr. Barbara Kreutzkamp

Maintz L et al. Association of single nucleotide polymorphisms in the diamine oxidase gene with diamine oxidase serum activities. Allergy 2011; 66: 893-902 